\title{
TREADMILL PERFORMANCE AND SELECTED PHYSIOLOGICAL CHARACTERISTICS OF WHEELCHAIR ATHLETES
}

\author{
H. K. A. LAKOMY, BSc, MA, I. CAMPBELL, BSc, MSc, C. WILLIAMS, BSc, MSc, PhD \\ Dept of P.E. and Sports Science, Loughborough University of Technology
}

\section{ABSTRACT}

The purpose of this study was to examine selected physiological characteristics and pushing performance over a distance of five kilometres $(5 \mathrm{~km})$ in twelve wheelchair athletes (10 paraplegics and 2 tetraplegics). The physiological tests and $5 \mathrm{~km}$ wheelchair time trials were performed on a motorised treadmill adapted for use by wheelchairs. The maximum oxygen uptake $\left(\dot{V O}_{2} \max \right)$ and $\% \dot{V V O}_{2}$ max utilised at a fixed speed equivalent to a blood lactate concentration of $4 \mathrm{mmol} .1-1$, identified as being of importance in successful able-bodied endurance performance, were also found to correlate highly with $5 \mathrm{~km}$ performance in wheelchair athletes. Low correlations were found between performance and mean $\% \dot{\mathrm{VO}}_{2}$ max utilised over the whole distance and between performance and oxygen uptake at a standard speed. The results also showed that the tetraplegics had lower physiological reserves than the paraplegics, with a much reduced maximum heart rate and ventilation. The findings indicate that a combination of physiological characteristics influence pushing performance in wheelchair athletes.

\section{INTRODUCTION}

The last decade has seen a sharp increase in the number of tetraplegic and paraplegic athletes participating in wheelchair sports. This has resulted in an improvement in the standards of performance (Steadward and Walsh, 1986). This increase in participation has also stimulated research on the physiological responses of wheelchair athletes to exercise. The results from some of this work show that athletes with spinal cord injuries generally have a lower $\dot{\mathrm{VO}}_{2}$ max for arm exercise than able-bodied athletes (Bar-Or and Zwiren, 1975; Glaser et al, 1980). This has been attributed, in part, to the reduced functional muscle mass available for exercise, and a suggestion supported by the common finding that the lower the level of the lesion the higher the value of $\mathrm{VO}_{2}$ max attained (Gass and Camp, 1979; Coutts et al, 1983; Wicks et al, 1983). In addition to having the least functional muscle mass tetraplegics have the greatest loss of the autonomic nervous system (Glaser et al, 1980). These facts help to explain the markedly lower maximum heart rate and ventilation in this group compared with paraplegics (Ekblom and Lundberg, 1968; Knuttson et al, 1973; Gass et al, 1980).

The increased knowledge from research on the wheelchair athlete has resulted in an improvement in the training techniques (Corcoran et al, 1980). These, in turn, have contributed to the improvements seen in performance. Although more information is now available on the physiological responses of wheelchair athletes to exercise, little has been done to relate these reponses to actual performance. In able-bodied athletes several physiological factors have been identified as being highly correlated with endurance performance, notably:- a high $\dot{\mathrm{VO}}_{2}$ max (Saltin and Åstrand, 1967; Davies and Thompson, 1979); the ability to utilise a high proportion of $\dot{\mathrm{V}}_{2} \max$ for long periods of time (Costill et al, 1973; Davies and Thompson, 1979; Sjödin and Schèle, 1982); running economy (Conley and Krahenbuhl, 1980; Sjödin and Schèle, 1982); and the ability to run at high speeds with low blood lactate concentrations (Sjödin and Jacobs, 1981; Kumagi et al, 1982). It also appears that distance runners maintain a

Address for correspondence:

H. K. A. Lakomy

Dept. of P.E. and Sports Science

University of Technology

Loughborough

Leics. LE11 3TU running pace which allows the utilisation of the largest $\% \dot{\mathrm{VO}}_{2}$ max which just avoids the exponential rise in blood lactate (Farrell et al, 1979). The purpose of the present study was to examine the relationship between some of these physiological characteristics and $5 \mathrm{~km}$ treadmill performance time for a group of wheelchair athletes.

\section{METHOD}

Twelve wheelchair athletes, ten paraplegics and 2 tetraplegics, volunteered to participate in this study. They all trained regularly and participated in a wide range of sporting activities, with five of the athletes competing at international level. The subjects were asked to perform two tests; (a) an incremental exercise test, and (b) a $5 \mathrm{~km}$ treadmill time trial. Both tests were performed on a motorised treadmill (Woodway model ELGZ) which was adapted for use by wheelchairs as shown in Fig. 1. The subject's own chair was attached to the slider mechanism at position A, which allowed freedom of movement of the wheelchair forwards and backwards but restricted sideways movements. A safety backstop did not permit the wheelchair to travel backwards off the treadmill belt, should the athlete stop pushing. Each subject was fully familiarised with wheelchair pushing on the treadmill and also the

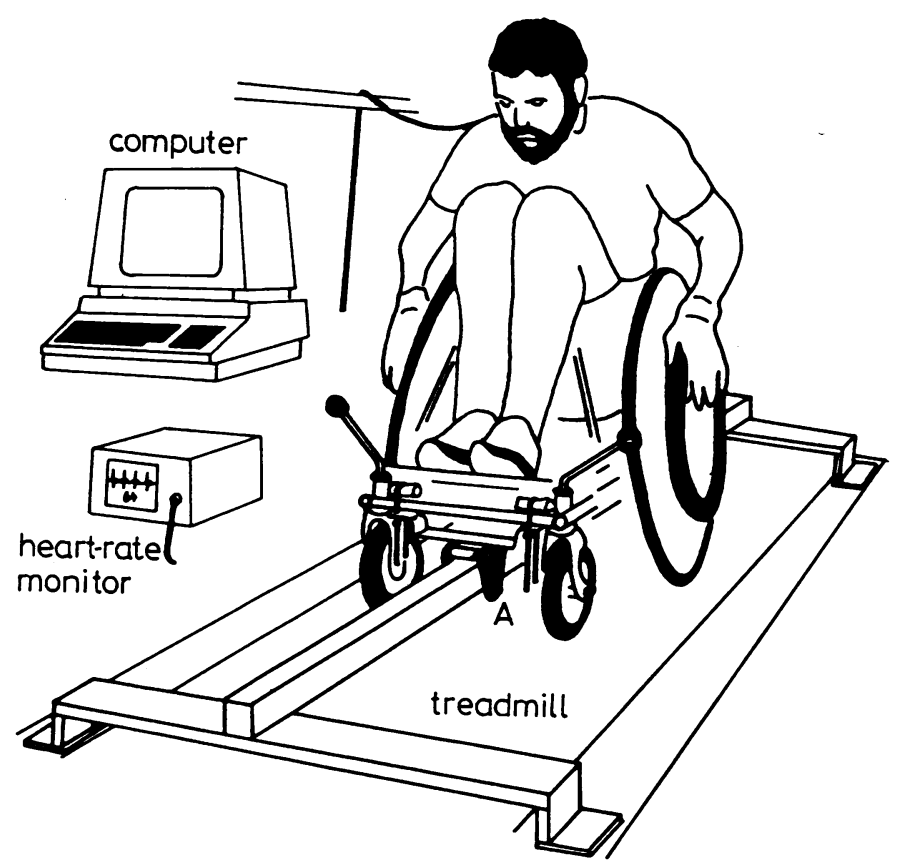

Fig. 1: The motorised treadmill wheelchair system. 
operation of the self-selection speed control which was used by the subjects to alter the treadmill belt speed during the $5 \mathrm{~km}$ test. The ability to push comfortably with the expired air collection apparatus is place was also checked before measurements were made.

A rolling start was employed for the $5 \mathrm{~km}$ time trial with the treadmill set at a submaximal speed of $3.5 \mathrm{~m} . \mathrm{s}^{-1}$. Once the test had started the subjects were able to adjust the treadmill speed using the self-select switch and were encouraged to cover the $5 \mathrm{~km}$ as quickly as possible. A single, incremental exercise test was adopted to determine the relationship between oxygen uptake, blood lactate and pushing speed for each individual. The test required each subject to push at each of four submaximal speeds for 4 minutes at each speed. At the conclusion of the fourth submaximal speed the athletes continued to push at a near maximal speed until voluntary exhaustion, for determination of $\mathrm{VO}_{2}$ max. The third treadmill speed, which was used as the reference speed, was determined for each athlete from the average pushing speed achieved between minutes 9 and 12 of the $5 \mathrm{~km}$ time trial. The first two speeds were $1 \mathrm{~m} . \mathrm{s}^{-1}$ and $0.5 \mathrm{~m} . \mathrm{s}^{-1}$, less than this reference speed. The fourth speed was the maximum speed achieved for 3-4 minutes during the $5 \mathrm{~km}$ time trial, with the final speed being a further 0.2-0.5 m.s $\mathrm{s}^{-1}$ faster.

During the last minute of each speed expired air was collected in Douglas Bags via a low resistance respiratory valve (Jakeman and Davies, 1979). At the end of each speed the subject stopped pushing and a thumbprick blood sample was taken for determination of blood lactate concentration. Each of the duplicate $25 \mu \mathrm{l}$ blood samples was deproteinised in $250 \mu \mathrm{l}$ of $2.5 \%$ perchloric acid, centrifuged and stored at $-20^{\circ} \mathrm{C}$. The subject recommenced pushing after one minute recovery, except after the fourth speed where the subject started pushing at the new speed as soon as the blood sample had been taken. The subject then pushed at this final speed, indicating when only one more minute of exercise could be achieved. Expired air was collected during this final minute and the test was then terminated. Throughout the tests heart rates were continuously monitored (Rigel Cardiac Memory Monitor 302). Expired air samples were analysed using a mass spectrometer (Centronic MGA200). The blood lactate concentrations were determined using a modification of Olsen's fluorometric procedure (Maughan, 1982).

Individual regression equations were calculated for the relationship between oxygen consumption and pushing speed and the oxygen cost of racing was estimated from these equations. In order to examine the inter-individual differences in pushing economy, the oxygen cost of pushing at a fixed speed of $4 \mathrm{~m} . \mathrm{s}^{-1}$ was also estimated from the regression equation. The speeds equivalent to a blood lactate concentration of $4 \mathrm{mmol}^{-\mathrm{I}^{-1}}$ were derived from the individual relationships between blood lactate concentration and pushing speed.

\section{RESULTS}

The physiological characteristics of the 12 subjects are shown in Table I. The value of $\dot{\mathrm{VO}}_{2}$ for the whole group was $1.82 \pm 0.47 \mathrm{I} . \mathrm{min}^{-1}$ (mean \pm S.D.) with all the values for the paraplegics being greater than those obtained for the two tetraplegics. Maximum values of ventilation and heart rate were lower for the tetraplegics than the paraplegics, with the tetraplegics exhibiting a plateau in ventilation at approximately $90 \%$ of maximum pushing speed (Fig. 2).
TABLE I

Levels of spinal lesion, age and physiological characteristics of the wheolchair athletes.

\begin{tabular}{|c|c|c|c|c|c|}
\hline Subject & $\begin{array}{l}\text { Lesion } \\
\text { Level }\end{array}$ & $\begin{array}{c}\text { Age } \\
\text { years }\end{array}$ & $\begin{array}{l}\mathrm{VO}_{2} \max \\
\text { I.min }^{-1}\end{array}$ & $\begin{array}{l}\dot{V}_{E \max } \\
I_{\text {I. }} \min ^{-1}\end{array}$ & $\begin{array}{c}\text { H.R. } \max \\
\text { b. } \min ^{-1}\end{array}$ \\
\hline \multicolumn{6}{|c|}{ Tetraplegics } \\
\hline $\mathbf{a}$ & C7 & 30 & 1.08 & 33.2 & 108 \\
\hline b & $\mathrm{C7}$ & 35 & 1.21 & 35.8 & 129 \\
\hline \multicolumn{6}{|c|}{ Paraplegics } \\
\hline c & T4 & 26 & 1.86 & 64.0 & 184 \\
\hline d & T4 & 24 & 1.71 & 56.8 & 206 \\
\hline e & $\mathrm{T} 11 / \mathrm{T} 12$ & 22 & 2.30 & 69.2 & 202 \\
\hline$f$ & $\mathrm{~T} 11 / \mathrm{T} 12$ & 15 & 1.50 & 69.8 & 196 \\
\hline $\mathbf{g}$ & L1 & 18 & 2.41 & 104.7 & 210 \\
\hline$h$ & L1 & 37 & 1.37 & 65.7 & 186 \\
\hline $\mathbf{i}$ & L1 & 25 & 2.47 & 67.0 & 162 \\
\hline j & L1 & 31 & 1.78 & 56.5 & 180 \\
\hline k & L1/L2 & 15 & 2.18 & 54.2 & 205 \\
\hline \multirow[t]{3}{*}{1} & L1/L2 & 22 & 1.91 & 60.0 & 198 \\
\hline & mean & 24 & 1.95 & 66.8 & 193 \\
\hline & \pm S.D. & 7 & 0.38 & 14.4 & 15 \\
\hline
\end{tabular}

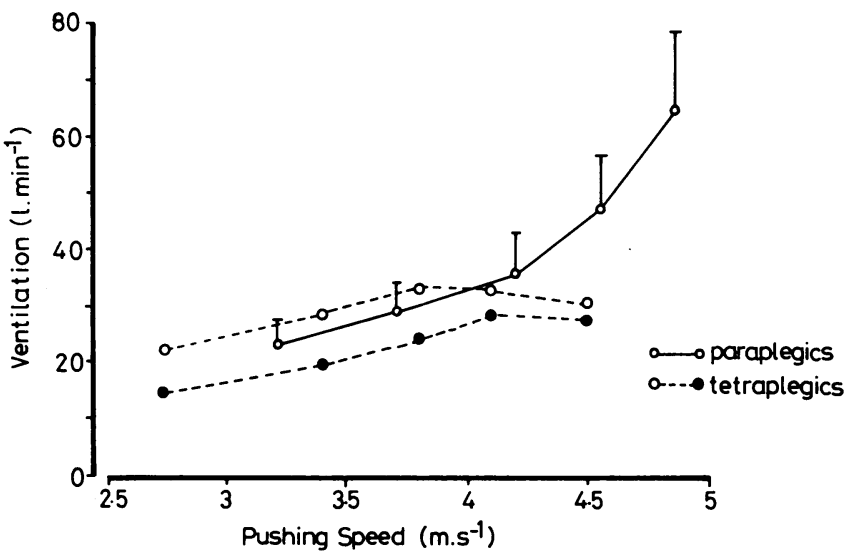

Fig. 2: The relationship between ventilation and pushing speed for the paraplegic group (mean \pm S.D.) and the two tetraplegics.

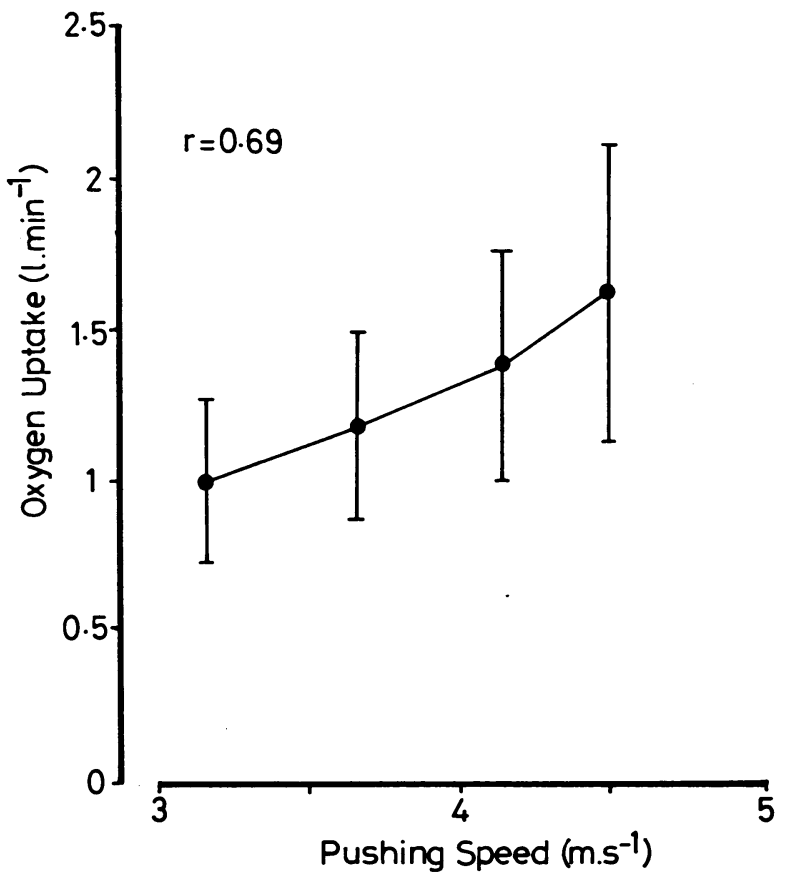

Fig. 3: The relationship between oxygen uptake and pushing speed for the whole group (mean $\pm S . D$., $n=12$ ). 
Pushing time and pace, estimated oxygen cost and estimated $\% \mathrm{VO}_{2}$ max at $5 \mathrm{~km}$ pace at $4 \mathrm{~m} . \mathrm{s}$ for the two tetraplegics and the paraplegic group (mean \pm S.D.).

\begin{tabular}{|c|c|c|c|c|c|c|c|}
\hline & & $\begin{array}{l}\text { Trial Time } \\
\text { (mins) }\end{array}$ & $\begin{array}{l}\text { Trial Pace } \\
\left(\mathbf{m}^{\left.-s^{-1}\right)}\right.\end{array}$ & $\begin{array}{l}\text { Est. } \mathrm{VO}_{2} \\
\text { (I.min-1) }\end{array}$ & $\begin{array}{c}\text { Est. } \% \dot{\mathrm{VO}} \mathrm{O}_{2} \max \\
(\%)\end{array}$ & $\begin{array}{l}\text { Est. } \% \dot{\mathrm{VO}_{2}} \\
\text { at } 4 \mathrm{~m} \cdot \mathrm{s}^{-1}\end{array}$ & $\begin{array}{l}\text { Est. } \% \dot{\mathrm{VO}_{2}} \max \\
\text { at } 4 \mathrm{~m} \cdot \mathrm{s}^{-1}\end{array}$ \\
\hline \multirow[t]{2}{*}{ Tetraplegics } & a & 20.57 & 4.07 & 1.03 & 95.4 & 1.01 & 92.3 \\
\hline & b & 24.00 & 3.47 & 1.03 & 85.1 & 1.13 & 92.6 \\
\hline \multirow[t]{2}{*}{ Paraplegics } & & 20.33 & 4.20 & 1.50 & 76.3 & 1.37 & 71.0 \\
\hline & & \pm 2.93 & \pm 0.69 & \pm 0.41 & \pm 11.1 & \pm 0.43 & \pm 20.0 \\
\hline
\end{tabular}

The oxygen cost of wheelchair pushing on the treadmill is shown in Fig. 3. A correlation of 0.69 was found between oxygen uptake and pushing speed $(p<0.05)$. The performance results and estimated oxygen consumptions are shown in Table II. The estimated mean $\% \dot{\mathrm{VO}}_{2}$ max utilised during the $5 \mathrm{~km}$ test, for all 12 athletes, was $79 \%$ (range $61 \%$ to $95 \%$ ). The mean pushing speed equivalent to a blood lactate concentration of $4 \mathrm{mmol}^{-\mathrm{I}^{-1}}$ was found to be $4.23 \pm 0.97 \mathrm{~m} . \mathrm{s}^{-1}$. This speed was not significantly different from the average speed $\left(4.13 \pm 0.65 \mathrm{~m} . \mathrm{s}^{-1}\right)$ which the subjects achieved during the $5 \mathrm{~km}$ test (V5 $\mathrm{km}$ ). The heart rate responses were significantly different between the groups ( $p<0.001)$ with the tetraplegics' heart rates markedly lower throughout the test (Fig. 4). All the athletes, however, were working at between 80 and $90 \%$ of their respective maximum heart rates.

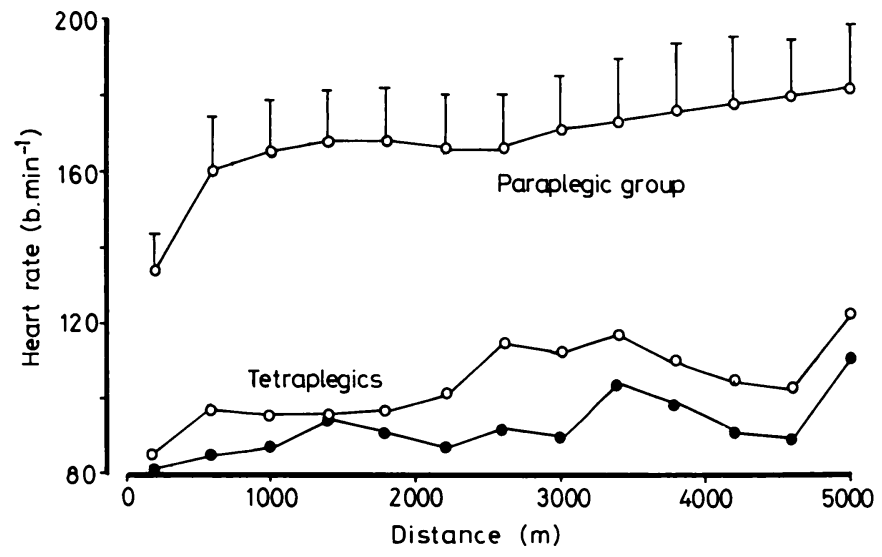

Fig. 4: Heart rate responses during the treadmill $5 \mathrm{~km}$ push for the paraplegic group (mean \pm S.D.) and the two tetraplegics.

\section{DISCUSSION}

The mean $\mathrm{VO}_{2}$ max value of $1.82 \mathrm{I} \cdot \mathrm{min}^{-1}$ for all the athletes is lower than the values reported for able-bodied athletes performing similar arm exercise (Bar-Or and Zwiren, 1975; Glaser et al, 1980). This may be explained, in part, by the reduced functional muscle mass available to the paraplegic and tetraplegic athletes. The mean values of $\mathrm{VO}_{2} \max$ and maximum heart rate for the paraplegic subjects are, however, comparable with those previously found in wheelchair athletes (Gass and Camp, 1979; Gass et al, 1980; Coutts et al, 1983; Wicks et al, 1983). The two tetraplegics in the group had lower values of $\mathrm{VO}_{2}$ max, maximum ventilation and maximum heart rate than the paraplegic athletes. However, their values were also similar to those reported in the literature for similar levels of spinal lesion (Ekblom and Lundberg, 1968; Gass and Camp, 1979; Coutts et al, 1983).

The difference in the heart rate response between the paraplegic and tetraplegic athletes during the $5 \mathrm{~km}$ test is due to the lack of sympathetic innervation to the heart in the tetraplegics. In the tetraplegic athlete the maximum heart rate is determined by the sinoatrial rhythm (Smith et al, 1976) and, therefore, the maximum heart rates would be

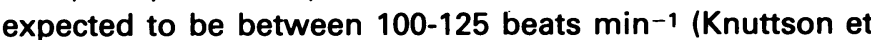
al, 1973). The two tetraplegics also had a lower maximal ventilation than the paraplegics (Table II). This is probably due to the reduced sympathetic innervation of the intercostal and abdominal muscles which are required for ventilation. Although ventilation has not been reported to limit $\mathrm{VO}_{2}$ max or performance in tetraplegics, ventilation did not increase with increasing intensity of effort in the two tetraplegics above approximately $90 \%$ of $\dot{\mathrm{vO}}_{2}$ max. This may indicate that ventilation is limiting maximum oxygen uptake. The paraplegic athletes, however, showed the exponential relationship between ventilation and intensity of exercise that is invariably found for able-bodied athletes.

The range of measured values of $\dot{\mathrm{VO}}_{2}$ max and the $5 \mathrm{~km}$ performance times for the wheelchair athletes were wide. A correlation coefficient of $0.61(p<0.05)$ was obtained between $\dot{\mathrm{VO}}_{2}$ max was correlated with $\mathrm{V}_{5} \mathrm{~km}$, thus indicating the importance of $\mathrm{VO}_{2}$ max for performance. This relationship has been well established in running (Davies and Thompson, 1979). When only the highly trained endurance athletes were considered the correlation between $\dot{\mathrm{VO}}_{2}$ max and $\mathrm{V} 5 \mathrm{~km}$ was increased to 0.77 . It should be noted, however, that these athletes used racing wheelchairs on the treadmill which may have been the factor influencing the correlation value. As only $37-59 \%$ of the variance is accounted for in these correlations, there are obviously other factors, such as wheelchair design, that contribute to performance. Running economy has been described as an "essential attribute to running success" (Conley and Krahenbuhl, 1980). In the present study the pushing economy of the athletes, defined as the oxygen cost of pushing at $4 \mathrm{~m} . \mathrm{s}^{-1}$, was correlated with V $5 \mathrm{~km}$. The low value of 0.39 was obtained for the correlation coefficient, indicating that pushing economy alone is not a major factor influencing performance. Pushing economy may, however, moderate the effect of $\dot{\mathrm{VO}}_{2} \max$ on performance.

Costill et al (1973) suggested that the percentage of maximum oxygen uptake utilised at a given speed may be a more important physiological characteristic influencing performance than running economy, and presumably pushing economy, per se. The ability to sustain a high percentage of one's $\mathrm{VO}_{2}$ max is, therefore, important in endurance events. In the present study a high correlation $(r=-0.84, p<0.05)$ was found between $\% \dot{V O}_{2}$ max utilised at $4 \mathrm{~m} . \mathrm{s}^{-1}$ and $5 \mathrm{~km}$ performance times. The estimated mean $\% \dot{V O}_{2}$ max sustained by the athletes during the $5 \mathrm{~km}$ push was $79 \%( \pm 13.2 \%)$. This value is similar to that reported by Williams and Nute (1983) for recreational runners during a half marathon, but is somewhat lower 
than the value of around $87 \% \mathrm{VO}_{2}$ max reported for a $5 \mathrm{~km}$ time trial (Ramsbottom et al, 1987). Although this ability is important to the individual, it should not be inferred that the mean $\% \mathrm{VO}_{2}$ max utilised over the performance distance can be used to account for performance differences in the whole group ( $r=0.08$ ).

In running studies the speed at which the onset of the accumulation of blood lactate occurs has been found to be an important indicator of performance (Farrell et al, 1979; Sjödin and Jacobs, 1981; Kumagi et al, 1982). In the present study a high correlation $(r=0.83, p<0.05$ ) was found between the speed at which the blood lactate concentration reached $4 \mathrm{mmol}^{-\mathrm{I}^{-1}}$ and average pushing speed. This value was even higher $(r=0.87, p<0.05)$ during the middle section of the test when the athletes were pushing at a fairly constant speed. This strong relationship between V4 mM and $5 \mathrm{~km}$ performance time has been reported for runners (Williams et al, 1985). It would appear that, as with running, the wheelchair athletes set a race pace which just avoids the exponential rise in blood lactate concentration.

In conclusion, the results of the present study suggest that the endurance performance of wheelchair athletes is influenced by several physiological characteristics and that the same methods that are used to characterise endurance runners can also be used to describe endurance wheelchair athletes. In addition it was clear that the tetraplegic athletes had lower functional capacities than the paraplegic athletes.

\section{References}

Bar-Or, O. and Zwiren, L. D., 1975 "Maximal oxygen consumption test during arm exercise - reliability and validity". J.Appl.Physiol. 38: 424-426.

Conley, D. L. and Krahenbuhl, G. S., 1980 "Running economy and distance running performance of highly trained athletes". Med.Sci.Sports 12: 357-360.

Corcoran, P. J., Goldman, R. f., Hoerner, E. F., Kling, C., Knuttgen, H. G. Marquis, B. C., McCann, B. C. and Rossier, A. B., 1980 "Sports medicine and the physiology of wheelchair marathon racing". Orthop.Clin.North Am. 11: 697-716.

Costill, D. L., Thomason, H. and Roberts, E., 1973 "Fractional utilisation of aerobic capacity during distance running". Med.Sci.Sports 5: 248-252.

Coutts, K. D., Rhodes, E. C. and McKenzie, D. C., 1983 "Maximal exercise responses or tetraplegics and paraplegics". J.Appl.Physiol. 55: 479-482.
Davies, C. T. M. and Thompson, M. W., 1979 "Aerobic performance of female marathon and male ultramarathon athletes". Eur.J.Appl.Physiol. 41: 233-245.

Ekblom, B. and Lundberg, A., 1968 "Effect of physical training on adolescents with severe motor handicaps". Acta Paediat.Scand. 57: 17-23.

Farrell, P. A., Wilmore, J. H., Coyle, E. F. and Costill, D. L., 1979 "Plasma lactate accumulation and distance running performance". Med.Sci.Sports 11 (4): 338-344.

Gass, G. C. and Camp, E. M., 1979 "Physiological characteristics of trained Australian paraplegic and tetraplegic subjects". Med.Sci.Sports 11: 256-259.

Gass, G. C., Watson, J., Camp, E. M., Court, H. J., McPherson, L. M. and Redhead, P., 1980 "The effects of physical training on high level spinal lesion patients". Scand.J.Rehab.Med. 12: 61-65.

Glaser, R. M., Sawka, M. N., Brune, M. F. and Wilde, S. W., 1980 "Physiological responses to maximal effort wheelchair and arm ergometry". J.Appl.Physiol. 48: 1060-1064.

Knuttsen, E., Lewenhaupt-Olsson, E. and Thorsen, M., 1973 "Physical work capacity and physical conditioning in paraplegic patients". Paraplegia 11: 205-216.

Kumagi, S., Tanaka, K., Matsuura, Y, Matsuzaka, A., Hirakoba, K. and Asano, K., 1982 "Relationships of the anaerobic threshold with the $5 \mathrm{~km}$, $10 \mathrm{~km}$ and 10 mile races". Eur.J.Appl.Physiol. 49: 13-23.

Maughan, R. J., 1982 "A simple rapid method for the determination of glucose, lactate, pyruvate, alanine, 3-hydroxybutyrate and acetoacetate on a single 20 $\mu$ l blood sample". Clin.Chim.Acta 122: 231-240.

Ramsbottom, R., Nute, M. and Williams, C., 1987 "Determinants of 5 km running performance in active men and women". Brit.J.Sports Med. In press.

Saltin, B. and Astrand, P.-O., 1967 "Maximal oxygen uptake in athletes". J.Appl.Physiol. 23: 353-358.

Sjödin, B. and Jacobs, I., 1981 "Onset of blood lactate accumulation and marathon running performance". Int.J.Sports Med. 2: 23-26.

Sjödin, B. and Schèle, R., 1982 "Oxygen cost of treadmill running in long distance runners". In: Exercise and Sport Biology. Ed. P. V. Komi. Human Kinetics. Champaign. U.S.A. pp. 61-67.

Smith, E. E., Guyton, A. C., Manninu, R. D. and Whitey, R. J. 1976 "Integrated mechanisms of cardiovascular response and control during exercise in the normal human". Prog.Cardiovasc.Dis. 18: 421-443.

Steadward, R. and Walsh, C., 1986 "Training and fitness programs for disabled athletes: past, present and future". In: Sport and Disabled Athlete. Ed. Sherrill, C. The 1984 Olympic Scientific Congress Proceedings. 9: 3-17.

Wicks, J. R., Olridge, M. B., Cameron, B. J. and Jones, N. L., 1983 "Arm cranking and wheelchair ergometry in elite spinal cord injured athletes". Med.Sci.Sports 15: 224-231.

Williams, C. and Nute, M., 1983 "Some physiological demands of a half marathon race on recreational runners". Brit.J.Sports Med. 17 (3): 152-161.

Williams, C., Ramsbottom, R., Boobis, L. and Freeman, W., 1985 "Maximum oxygen uptake, muscle fibre composition and running performance". Clin.Physiol. 5 (4): 172. 